\title{
PENGARUH DIGITAL MARKETING DAN BRAND AWARENESS TERHADAP KEPUTUSAN PEMBELIAN PADA STARTUP BIKE RENTAL BANANAZ BALI
}

\author{
Alicia Sastra Millennium ${ }^{1}$, I Wayan Suardana ${ }^{2}$, I Made Kusuma Negara ${ }^{3}$ \\ Email: aliciasastra@gmail.com ${ }^{1}$, suar.dana@yahoo.co.id ${ }^{2}$, kusuma.negara@unud.ac.id ${ }^{3}$ \\ ${ }_{1,2,3}$ Program Studi Industri Perjalanan Wisata, Fakultas Pariwisata, Universitas Udayana
}

\begin{abstract}
The increase in international tourist every year on the island of Bali is used by tourism entrepreneurs to help the government increase regional and the state revenues. The need for transportation for travel activities provides an opportunity for Bananaz Bali to launch the first rental application in Bali. Based on Start-up, Bananaz Bali applies digital marketing and is also assisted by implementing brand awareness activities. This study requires 75 respondents with the criteria of over the age of 18 years old, and have already used Bananaz Bali services. All the data collected through questionnaires and then processed using data analysis techniques SEM Partial Least Square. The results of this study are: 1) There is a positive and significant relationship between digital marketing variable and brand awareness. 2) There is a negative and insignificant relationship between digital marketing variable on purchasing decisions. 3) Against a positive and significant relationship between brand awareness and purchasing decisions.
\end{abstract}

\begin{abstract}
Abstrak : Adanya kenaikan wisatawan mancanegara setiap tahunnya di Pulau Bali, dimanfaatkan oleh para pengusaha pariwisata untuk membantu pemerintah meningkatkan pendapatan daerah dan negara. Dibutuhkannya transportasi untuk kegiatan berwisata memberikan peluang bagi Bananaz Bali untuk merilis aplikasi rental kendaraan pertama di Bali. Karena berbasis Start-up, Bananaz Bali menerapkan pemasaran secara digital dan dibantu juga dengan menerapkan kegiatan brand awareness. Penelitian ini membutuhkan 75 responden dengan kriteria berumur diatas 18 tahun dan sudah pernah memakai jasa Bananaz Bali. Data yang dikumpulkan melalui kuesioner kemudian diolah menggunakan teknik analisis data SEM Partial Least Square. Hasil penelitian ini adalah: 1) Terdapat hubungan yang positif dan signifikan antara variabel digital marketing terhadap brand awareness. 2) Terdapat hubungan yang negatif dan tidak signifikan antara variabel digital marketing terhadap keputusan pembelian. 3) Terhadap hubungan yang positif dan signifikan antara brand awareness terhadap keputusan pembelian.
\end{abstract}

Keywords: digital marketing, brand awareness, purchase decision, startup bike rental. 


\section{PENDAHULUAN}

Pariwisata merupakan suatu perjalanan yang bertujuan untuk mendapatkan sebuah kenikmatan, mencari kepuasan, mengetahui sesuatu, memperbaiki kesehatan, menikmati olahraga atau istirahat, menunaikan tugas, berziarah dan tujuan lainnya (James J. Spillane). Berdasarkan data dari Badan Pusat Statisik, provinsi yang paling sering dikunjungi oleh para turis di Indonesia adalah Bali dan selalu terjadi kenaikan wisatawan mancanegara setiap tahunnya. Bali harus mampu memanfaatkan keadaan seperti ini karena pariwisata merupakan sector yang ikut berperan penting dalam usaha peningkatan pendapatan. Saat berwisata di Bali, berkeliling menggunakan transportasi umum bukan menjadi pilihan utama wisatawan karena transportasi umum sulit menjangkau destinasi wisata. Beberapa alasan wisatawan lebih memilih menggunakan jasa sewa motor saat berwisata di Bali adalah karena dengan menyewa motor merupakan pilihan yang paling murah, lebih cepat, efektif, fleksibel, dan memberikan banyak kebebasan waktu dan jadwal. Startup Bananaz.co merilis aplikasi rental kendaraan pertama di Bali. Definisi startup digital adalah sekumpulan individu yang membentuk organisasi sebagai perusahaan rintisan yang menghasilkan produk dalam bidang teknologi (Yevgeniy Brikman 2015). Bananaz Bali menerapkan sistem reservasi menggunakan perangkat lunak atau aplikasi yang dirancang sendiri untuk mempermudah pelayanan, hal ini menjadi perbedaan yang signifikan Bananaz Bali dengan rental motor lainnya. Selain itu, strategi pemasaran yang diterapkan oleh Bananaz Bali dengan membuat semua armadanya berwarna kuning sangat menuju pada terciptanya Brand Awareness, agar produk yang dipasarkan dapat diingat dengan mudah oleh pasar. Pengaruh digital marketing dan brand awareness ini dapat mempengaruhi keputusan pembelian calon konsumen Bananaz Bali.

\section{METODE}

Studi ini dilakukan di Perusahaan Bananaz Bali yang berlokasi di Jl. Pengubengan Kauh no. 36B, Kerobokan Kelod, Kuta Utara, Badung, Bali. Digital marketing, brand awareness, dan keputusan pembelian adalah variabel utama dalam penelitian ini. Variabel digital marketing terbagi atas 4 indikator yaitu biaya dan waktu, program unggulan, desain halaman, dan interaktif (Eun Young Kim 2002), variabel brand awareness terbagi atas 4 indikator yaitu daya ingat merek, pengenalan merek, keputusan pembelian merek, pemakaian merek (Krisyantono 2006:26), dan variabel keputusan pembelian terbagi menjadi 5 indikator yaitu pengenalan kebutuhan, pencarian informasi, evaluasi aternatif, keputusan pembelian, dan perilaku pasca pembelian (Kotler 1985). Teknik pengumpulan data yang digunakan pada penelitian ini adlaah kuesioner, yang disebarkan melalui google form, dan juga wawancara kepada bagian sales marketing perusahaan Bananaz Bali untuk informasi pendukung. Teknik penentuan sampel menggunakan cara purposive sampling, dengan kriteria wisatawan yang pernah menggunakan jasa Bananaz Bali minimal satu kali dan berusia minimal 16 tahun dan responden yang dibutuhkan penelitian ini berjumlah 75 orang. Teknik analisis data penelitian ni yaitu dengan uji persamaan strukturan berbasis variance atau Partial Least Square (PLS) menggunakan software SmartPLS.

\section{HASIL DAN PEMBAHASAN}

Berdasarkan data yang diperoleh dari hasil kuesioner, diketahui bahwa jumlah responden pria lebih banyak dibanding responden wanita. Jumlah responden pria sebanyak 50 orang $(66,7 \%)$ dan wanita sebanyak 25 orang $(33,3 \%)$. Sebagian besar responden berumur 26-35 tahun (48\%), 16-25 tahun (38,7\%), 36-45 tahun (12\%), dan 46-55 tahun (1,3\%). Kemudian, sebanyak 53 orang $(70 \%)$ datang ke Bai dengan tujuan berwisata, 15 orang (20\%) datang dengan tujuan bisnis, dan 4 orang $(6 \%)$ dengan tujuan mengunjungi keluarga dan 3 orang (4\%) lainnya datang dengan tujuan lainnya.

Dalam teknik pengolahan data berbasis Partial Least Square, diperlukan 2 tahap untuk menilai Fit Model dari sebuah model penelitian (Ghozali, 2006) yaitu dengan cara menilai Outer model, dan Inner model. Untuk menilai outer model, harus dilakukan analisa convergent validity, discriminant validity, dan composite reliability. Sedangkan dalam inner model, akan dilakukan model structural yang akan dievaluasi dengan R.square.

Outer Loadings

Untuk penelitian tahap awal dair pengembangan skala pengukuran nilai loading 0,5 sampai 0,6 dianggap cukup memadai (Chin 
1998 dalam Ghozali 2006) namun dalam penelitian ini digunakan batas loading factor sebesar 0,70 .

Tabel 1

Outer Loadings (Measurement Model)

\begin{tabular}{lll}
\hline \multicolumn{2}{l}{ Model Awal } & Modifikasi \\
\hline Digital Marketing \\
\hline X1.1 & 0.728 & 0.706 \\
\hline X1.2 & 0.788 & 0.807 \\
\hline X1.3 & 0.823 & 0.828 \\
\hline X1.4 & 0.780 & 0.767 \\
\hline \multicolumn{3}{c}{ Model Awal } \\
\hline Brand Awareness \\
\hline X2.1 & 0.801 & Modifikasi \\
\hline X2.2 & 0.730 & 0.850 \\
\hline X2.3 & 0.759 & 0.776 \\
\hline X2.4 & 0.639 & 0.812 \\
\hline X2.5 & 0.814 & 0.786 \\
\hline X2.6 & 0.696 & \\
\hline \multicolumn{3}{c}{ Model Awal } \\
\hline Keputusan Pembelian \\
\hline Y1.1 & 0.476 \\
\hline Y1.2 & 0.656 & Modifikasi \\
\hline Y1.3 & 0.754 & 0.881 \\
\hline Y1.4 & 0.802 & 0.909 \\
\hline Y1.5 & 0.823 & 0.865 \\
\hline
\end{tabular}

Sumber : Data diolah, 2020.

\section{Discriminant Validity}

Discriminant validity dilakukan untuk memastikan bahwa setiap konsep dari masingmasing variabel laten berbeda dengan variabel lainnya. Discriminant validity dinyatakan baik jika setiap nilai loading dari setiap indicator dari sebuah variabel laten memiliki nilai loading yang paling besar dengan nilai loading lain terhadap variabel laten lainnya.

Tabel 2

Nilai Discriminant Validity

\begin{tabular}{llll}
\hline & DM & BA & KP \\
\hline $\mathrm{X} 1.1$ & 0.706 & 0.417 & 0.261 \\
\hline $\mathrm{X} 1.2$ & 0.807 & 0.601 & 0.547 \\
\hline $\mathrm{X} 1.3$ & 0.828 & 0.503 & 0.421 \\
\hline $\mathrm{X} 1.4$ & 0.767 & 0.423 & 0.186 \\
\hline $\mathrm{X} 2.1$ & 0.389 & 0.850 & 0.573 \\
\hline $\mathrm{X} 2.2$ & 0.598 & 0.776 & 0.423 \\
\hline $\mathrm{X} 2.3$ & 0.539 & 0.812 & 0.496 \\
\hline $\mathrm{X} 2.5$ & 0.514 & 0.786 & 0.471 \\
\hline $\mathrm{Y} 1.3$ & 0.529 & 0.631 & 0.881 \\
\hline
\end{tabular}

\begin{tabular}{llll}
\hline Y1.4 & 0.376 & 0.528 & 0.909 \\
\hline Y1.5 & 0.375 & 0.440 & 0.865 \\
\hline
\end{tabular}

Sumber : Data diolah, 2020.

\section{Reliability dan Average Variance Extracted (AVE)}

Konstruk dikatakan memiliki reliabilitas yang tinggi jika nilainya 0,70 dan AVE berada diatas 0,50 .

Tabel 3

Composite Reliability dan AVE

\begin{tabular}{lrr}
\hline & $\begin{array}{c}\text { Composite } \\
\text { Reliability }\end{array}$ & $\begin{array}{c}\text { Average Variance } \\
\text { Extracted }\end{array}$ \\
\hline DM & 0.860 & 0.606 \\
\hline BA & 0.881 & 0.650 \\
\hline KP & 0.916 & 0.784 \\
\hline
\end{tabular}

Sumber : Data diolah, 2020.

\section{Inner Model}

Pengujian inner model atau model struktural dilakukan untuk melihat hubungan antar konstruk. Nilai signifikansi dan R-square dari model penelitian.

\section{Gambar 1}

Model Struktural

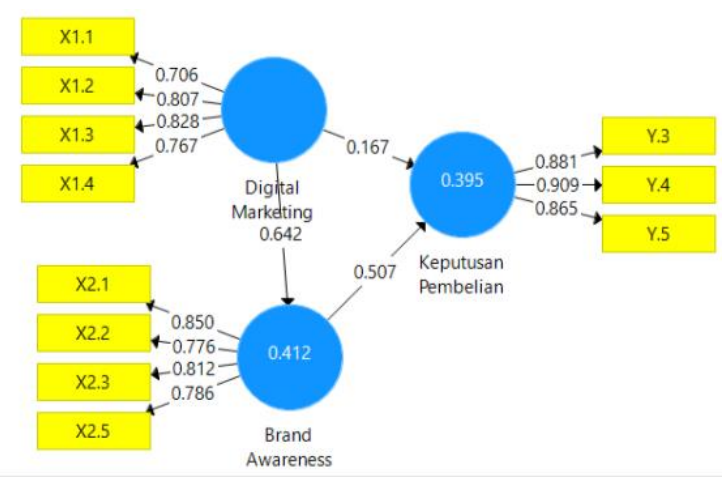

Sumber : Data diolah, 2020.

\section{R-square}

Model structural dievaluasi dengan menggunakan R-square untuk konstruk dependen uji t serta signifikansi dari koefisien parameter jalur structural. 
Tabel 4

Nilai R-Square

\begin{tabular}{lr}
\hline & $R$-Square \\
\hline Brand Awareness & 0.412 \\
\hline Keputusan & 0.395 \\
Pembelian & \\
\hline Sub $:$ Data dian
\end{tabular}

Sumber : Data diolah, 2020.

\section{Pengujian Hipotesis}

Dilakukan metode bootstrap terhdap sampel untuk meminimalkan masalah ketidaknormalan data penelitian.

Tabel 5

Pengujian Hipotesis

\begin{tabular}{cccrr}
\hline & O & M & STDEV & $\mid$ O /STDEV $\mid$ \\
\hline $\begin{array}{c}\text { DM } \\
->\end{array}$ & 0.642 & 0.655 & 0.066 & 9.802 \\
BA & & & & \\
\hline $\begin{array}{c}\text { DM } \\
->\end{array}$ & 0.167 & 0.174 & 0.136 & 1.228 \\
KP & & & & \\
\hline BA & 0.507 & 0.510 & 0.119 & 4.261 \\
$->$ & & & & \\
KP & & & & \\
\hline
\end{tabular}

Sumber : Data diolah, 2020.

\section{Hasil Uji Hipotesis}

Hasil pengujian hipotesis pertama menunjukkan bahwa hubungan variabel digital marketing dengan brand awareness menunjukkan koefisien jalur sebesar 0.642 dengan nilai $\mathrm{t}$ sebesar 9.802. Nilai tersebut lebih besar dari t tabel 1,960. Hasil ini berarti bahwa digital marketing memiliki pengaruh yang positif dan signifikan terhadap brand awareness pada Bananaz bali. Maka dar itu Hipotesis 1 diterima. Selanjutnya pada hipotesis kedua menunjukkan bahwa hubungan variabel digital marketing dengan keputusan pembelian menunjukkan koefisien jalur sebesar 0.167 dengan nilai t sebesar 1.228. nilai tersebut lebih kecil dari t tabel 1,960. Hasil ini berarti bahwa digital marketing memiliki pengaruh yang negatif dan tidak signifikan terhadap keputusan pembelian yang berarti tidak sesuai dengan hipotesis kedua maka dari itu Hipotesis 2 tidak diterima. Yang terakhir pada hipotesis ketiga menunjukkan bahwa hubungan variabel brand awareness dengan keputusan pembelian menunjukkan nilai koefisien jalur sebesar 0.507 dengan nilai $t$ sebesar 4.261. Nilai tersbut lebih besar dari $\mathrm{t}$ tabel 1,960. Hasil ini berarti bahwa brand awareness memiliki hubunga yang positif dan signifikan terhadap keputusan pembelian pada Bananaz bali sesuai dengan hipotesis ketiga. Maka dari itu Hipotesis 3 diterima.

\section{SIMPULAN DAN SARAN Simpulan}

Berdasarkan hasil analisis dan pembahasan, dapat ditarik kesimpulan bahwa terdapat hubungan yang positif dan signifikan antara digital marketing terhadap brand awareness. Hal ini berarti bahwa perusahaan yang menerapkan pemasaran secara digital akan membangun dan meningkatkan brand awareness terhadap suatu brand atau merek perusahaan itu sendiri. Yang kedua, terhadap hubungan yang negative dan tidak signifikan antara digital marketing terhadap keputusan pembelian. Hal ini berarti bahwa pemasaran secara digital tidak memiliki pengaruh yang positif dan signifikan untuk melakukan keputusan pembelian pada konsumen potensial. Simpulan yang terakhir, terdapat hubungan yang positif dan siginifikan antara brand awareness terhadap keputusan pembelian. Hal ini berarti bahwa brand awareness atau kesadaran merek akan suatu perusahan, akan berpengaruh dalam tejadi proses keputusan pembelian konsumen potensial.

\section{Saran}

Penelitian selanjutnya hendaknya dapat menggunakan lebih banyak sampel sehingga dapat memperluas hasil data. Penelitian selanjutnya hendaknya melakukan uji prasampling kuesioner, karena dalam penelitian ini terdapat banyak indikator ynag dihapus karena bersifat tidak valid. Kepada pengelola Bananaz Bali untuk lebih mengembangkan digital marketing yang dilakukan agar dapat menjangkau lebih banyak konsumen dan mempengaruhi keputusan pembalian calon konsumen secara signifikan. 


\section{Kepustakaan}

Chin, W. W. (1998). The partial least squares approach for structural equation modeling. In G. A. Marcoulides (Ed.), Methodology for business and management. Modern methods for business research (p. 295-336). Lawrence Erlbaum Associates Publishers.

Eun Young Kim, Y.-K. K. 2002. Predicting online purchase intentions for clothing products, 883-897

Kriyantono, Rachmat. 2006. Teknik Praktis Riset Komunikasi. Jakarta : Kencana Prenada Media Group.

Spillane, James J. 1982:20. Pariwisata Indonesia, Sejarah, dan Prospeknya.

Yevgeniy Brikman. 2015. Hello Startup. O'Reilly Media ; 1 st edition. 